\title{
ПОДГОТОВКА СТУДЕНТОВ ЦИКЛИЧЕСКИХ ВИДОВ СПОРТА (НА ПРИМЕРЕ ЛЫЖНЫХ ГОНОК И БЕГА НА ДЛИННЫЕ ДИСТАНЦИИ) В УСЛОВИЯХ ТЕХНИЧЕСКОГО ВУЗА
}

\section{STUDENTS OF CYCLIC SPORTS \\ (ON THE EXAMPLE OF SKI RACING \\ AND LONG-DISTANCE RUNNING) IN THE CONDITIONS OF A TECHNICAL UNIVERSITY \\ I. Mosin \\ I. Mosina \\ M. Esaulov}

Summary: This work is devoted to the peculiarities of training students of cyclic sports on the example of cross-country skiing and longdistance running, in physical culture lessons in a technical university. The technique of roller skiing in the classroom with a student during the snowless period has been developed. The analysis of the effectiveness of running (cross) use on very rough terrain, for the development of the cardiovascular, respiratory systems and the musculoskeletal system, which is most important for students of cyclic sports, as it allows them to fulfill control standards and successfully perform at student competitions and cross-country skiing and long-distance running (runs, crosses), in training load mode.

Keywords: health, physical culture, roller skis, cross, rough terrain, novelty, cardiovascular system, respiratory system, musculoskeletal system.
Мосин Игорь Васильевич

К.п.н., дочент, ФГАОУ ВО «Национальный исследовательский ядерный университет «МИФИ»,

Москва

mosin59@mail.ru

Мосина Ирина Николаевна

Преподаватель, ФГАОУВО «Национальный исследовательский ядерный университет «МИФИ»,

Москва

trenermosina@yandex.ru

Есаулов Михаил Николаевич

К.т.н., доцент, ФГАОУ ВО «Национальный исследовательский ядерный университет «МИФИ»,

Москва

mesaulov@mail.ru

Аннотация: Данная работа посвящена особенностям подготовки студентов циклических видов спорта на примере лыжных гонок и бега на длинные дистанции, на занятиях физической культуры в условиях технического вуза. Разработана методика применения лыжероллеров на занятиях со студента в период бесснежья. Проведен анализ эффективности использования бега (кросс) по сильно пересеченной местности, для развития сердечно-сосудистой, дыхательной систем и опорно-двигательного аппарата, что наиболее важно для студентов циклических видов спорта, так как позволяет выполнить контрольные нормативы и успешно выступать на студенческих соревнованиях и по лыжным гонках и в беге на длинные дистанции (пробеги, кроссы), в режиме учебной нагрузки.

Ключевые слова: здоровье, физическая культура, лыжероллеры, кросс, сильнопересеченная местность, новизна, сердечно-сосудистая система, дыхательная система, опорно-двигательный аппарат.

этого можно достичь при условии, если занятия носят выраженный тренировочный характер. Рациональное построение учебного процесса на выносливость, в условиях технического вуза, позволит подвести организм студента к уровню оптимальной работоспособности, что в свою очередь обеспечит наиболее эффективную подготовленность.

\section{Анализ послехних публикаший}

Автор [5] считает, что в основу успешной сдачи нормативов на выносливость должно лечь комплексное использование всех средств тренировки. Наиболее эффективными средствами формирования общей выносливости он считает длинный бег и кроссы с различной интенсивностью, автор [10] предполагает, что самым эффективным средством для развития выносливости у 
студентов является ходьба на лыжах. На данный момент существует распространенная точка зрения, что для повышения общей выносливости необходимо использовать слабоинтенсивные продолжительные нагрузки, которые положительно влияют на сердечно-сосудистую и дыхательную системы и опорно-двигательный аппарата. На данный момент авторы рассматривают вопрос подготовки студентов в гуманитарных вузах, без учета специфики обучения студентов технического вуза. Поэтому, проблема организации занятий со студентами циклических видов спорта в техническом вузе, весьма значима и недостаточна решена, и мало описана.

\section{Актуальность}

На ряду, с воспитанием основных физических качеств $[1,2,3,5]$, формирования здорового образа жизни, привлечение студентов к регулярным занятиям физической культурой и спортом является наиболее актуальной [3]. Задача вуза искать эффективные средства и методы для развития выносливости студентов. [6,7,8,9]. Применение концентрированной нагрузки у студентов для развития выносливости, с применением небольшого количества средств (мишени) [4], позволит увеличить результативность тренировочной работы, при ограниченной часовой учебной нагрузки. Использование методики концентрированной нагрузки $[4,6,7]$, в процессе обучения, в группе циклических видов спорта, в условиях технического вуза, в данный момент, является наиболее актуальным, так как решает все эти задачи. Особенностью экспериментальной методики является применение ограниченного количества тренировочных средств, которые эффективно развивают выносливость (бег в гору, использование лыжероллеров в бесснежье, кросс по сильнопересеченной местности) $[8,9,10,11]$. Показано положительное влияние экспериментальной методики на физическое состояние студентов циклических видов спорта, что подтверждается достоверным повышением функционального состояния сердечно-сосудистой, дыхательной систем. Положительное влияние концентрированной тренировочной нагрузки на организм человека установлено многими исследователями $[4,6,7]$. Однако вопросы, связанные с применением данных упражнений в рамках академических занятий физической культурой со студентами группы циклических видов спорта, требуют дальнейшего изучения и уточнения. Применения данной методики позволит существенно расширить эффективность средств и методов в повышении уровня функционального состояния сердечно-сосудистой и дыхательной систем, а также позволит выполнить контрольные нормативы и успешно выступать на студенческих соревнованиях.

\section{Шель исследования:}

- является улучшение результатов на выносливость, на занятиях в учебно-тренировочном процессе студентов вуза, с использованием концентрированной тренировочной нагрузки с локомоторной направленностью, и экспериментально подтвердить эффективность их применения в условиях педагогического эксперимента;

\section{ЗаАачи исслеАования:}

- улучшить результаты сдачи контрольных нормативов на выносливость

- выявить эффективность сердечно-сосудистой и дыхательной систем и опорно-двигательного аппарата;

- снизить ЧСС на занятиях в учебно-тренировочном процессе;

\section{Организашия и методы исследования}

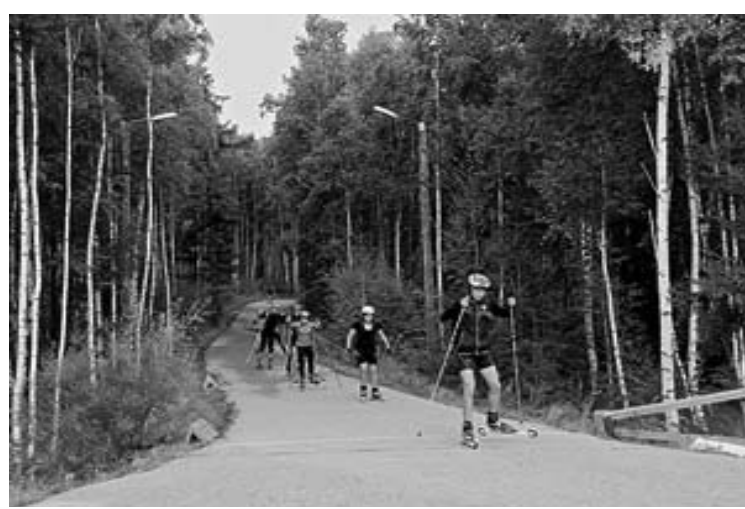

Рис. 1.

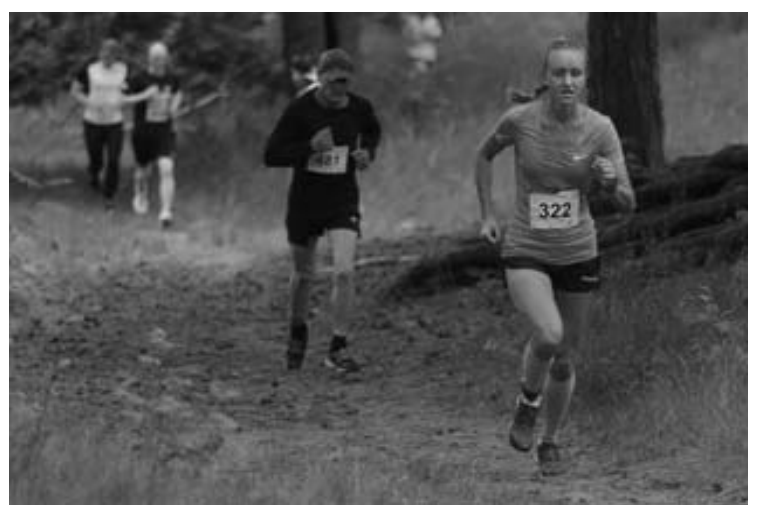

Рис. 2.

Занятия со студентами циклических видов спорта проводили на базе парка Коломенское, здесь присутствует асфальтированная трасса рис 1, а также сильнопересеченная местность с крутыми длинными подъемами рис.2. Что наиболее важно при организации занятий со студентами при ограниченном времени. Занятия проводились в режиме учебного занятия.

\section{Методика обучения при использовании коншентрированной нагрузки}

Для эксперимента мы разделили студентов на две 
группы. Одна выполняла нагрузку с применением лыжной подготовки, вторая группа использовала кроссовую подготовку.

Студенты первой группы (9 человек) выполняли нагрузку на лыжероллерах на пульсе не превышающем 160 уд/м. (8-12 км + 3-4х1000м(3,20-3,50+прыжки в гору 3-5+100-300м). Студенты второй группы (9 человек) выполняли нагрузку в беге по сильнопересеченной местности на пульсе не превышающем 160 уд/м. (6-10 км + $3 \times 1000$ м (3,20-3,50)+прыжки в гору 3-5+100-300м). Занятия проводили дважды в неделю в течение семестра, и одна тренировка выполнялась самостоятельно в виде восстановительного кросса. В конце тренировочной нагрузки обе группы выполняли прыжки в гору. Девушки выполняли нагрузку на 10-15\% меньше, как по объему, так и по интенсивности

Каждая группа получала задание на тренировку с учетом индивидуальных особенностей развития организма студента, контроль осуществляли пульсометрами (Polaris), поэтому каждый студент мог контролировать свое состояние по пульсу.

Подготовку мы разделили на 3 этапа, Втягивающий, Развивающий, Реализационный.

На первом этапе студенты выполняли малоинтенсиную работу на пульсе до 140 уд/мин, в течении 4 недель (сентябрь). (8км +5-6х500м (1,45-2,00)+прыжки 3х100м) На втором этапе нагрузка значительно увеличилась, как по объему, так и по интенсивности и пульс до 160 уд/мин (октябрь-ноябрь). (8-12 км + 3-4х1000м(3,20-3,350) прыжки в гору 5Х300м) При этом в середине октября студенты принимают участие в соревнованиях по кроссу.

Третий этап соревновательный (декабрь-январь), где студенты принимают участие в соревнованиях, как по легкой атлетике, так в лыжных гонках (при условии снега).

Перед началом эксперимента все студенты прошли медобследоание, противопоказаний для занятий не выявили, контрольное тестирование проводили после каждого этапа подготовки.

В результате проведенного нами эксперимента, мы выявили следующие:

- в группе студентов, выполнявших нагрузку на лыжероллерах, произошли изменения в адаптации к тренировочной работе от этапа к этапу по нарастающей, более плавно, результаты контрольных нормативов повышались равномерно (таб.1). Эффект от работы на сохранялся до 1,5 месяцев;

- в группе студентов, выполнявших нагрузку в виде бега по сильнопересеченной местности, мы видим, что во втором периоде (Развивающий), в первой его части, наблюдается незначительное ухудшение результатов тестирования (таб.1), это связано на наш взгляд с более сильным (концентрированным) воздействием тренировочной нагрузки на адаптацию организма студентов. Но впоследствии эффект от бега по сильно пересеченной местности сохранялся намного дольше до 2 месяцев.

\section{Результаты исследования}

Применение на занятиях по физической культуре в циклическом отделении (лыжероллеров), в позволило студентам более рационально адаптироваться к предлагаемой нагрузке и быть непосредственно вовлеченным в учебный процесс по улучшению своего здоровья, объективно контролировать свое самочувствие, датчиками чСС.(Polar) Это дает возможность оперативно повышать или понижать нагрузку в предлагаемой тренировочной программе, не боясь получить отрицательный эффект от перенапряжения сердечно-сосудистой и дыхательной систем. Использование кроссового бега по сильно пересеченной местности, более острая тренировочная нагрузка, она позволяет не только значительно улучшить показатели в беге на выносливость при сдаче нормативов, но и улучшить показатели сердечно-сосудистой, дыхательной и опорно-двигательного аппарата. Выполнение локомоторных упражнений с использованием лыжероллеров и кроссового бега по сильнопересеченной местности, позволяет значительно повысить интерес к занятиям физической культуры среди студентов циклического отделения, в условиях технического ВУЗа.

\section{Выво $\Delta ы$}

В техническом вузе, при работе со студентами, циклического отделения, на занятиях с применением лыжероллеров мы выявили, что адаптация к тренировочным нагрузкам происходит постепенно, что положительно сказывается на организм студентов. Результаты на выносливость показывают положительную динамику. Эту нагрузку можно рекомендовать студентам, не имеющим специально спортивной подготовки. Использование кроссового бега по сильнопересеченной местности является наиболее сильным воздействием на организм спортсменов, поэтому результаты на выносливость имеют скачкообразную тенденцию, вначале снижение результатов, затем стабилизацию и резкого возрастания. Этот вид нагрузки можно рекомендовать наиболее подготовленным студентам. С помощью упражнений локомоторных упражнений (лыжероллеров и кросс по сильнопересеченной местности) значительно улучшают показатели сердечно-сосудистой и дыхательной систем, это экспериментально подтверждается проведенными нами исследованиями, улучшаются результаты на выносливость при тестировании, снижается ЧСС и улуч- 
Таблица 1.

\begin{tabular}{|c|c|c|c|c|c|}
\hline № & Ф.И.0. & $\begin{array}{l}\text { Втягивающй этап } \\
\text { (сентябрь) }\end{array}$ & $\begin{array}{l}\text { Развивающий этап } \\
\text { (октябрь-ноябрь }\end{array}$ & $\begin{array}{l}\text { Реализационный этап } \\
\text { (декабрь-январь) }\end{array}$ & $\begin{array}{l}\text { Среднее } \\
\text { значение }\end{array}$ \\
\hline \multicolumn{2}{|c|}{ Лыже-роллеры } & $\begin{array}{c}1 \text { тест: } 2 \text { Ккм(д), 3км (м) } \\
4 С C, A Д\end{array}$ & $\begin{array}{c}2 \text { тест: } 2 \text { 2км(д), Зкм (M) } \\
4(C, A Д\end{array}$ & $\begin{array}{c}3 \text { тест: } 2 \text { 2км(д), Зкм (м) } \\
\text { чСС,АД }\end{array}$ & \\
\hline 1 & Мин-ов & $\begin{array}{c}11,30 / 140 \\
140 / 115\end{array}$ & $\begin{array}{c}11,17 / 135 \\
135 / 110\end{array}$ & $\begin{array}{c}10,57 / 120 \\
130 / 105\end{array}$ & $-33 c$ \\
\hline 2 & Вор-нов & $\begin{array}{c}11,43 / 145 \\
145 / 120\end{array}$ & $\begin{array}{c}11,26 / 138 \\
137 / 115\end{array}$ & $\begin{array}{c}11.05 / 124 \\
133 / 111\end{array}$ & $-38 c$ \\
\hline 3 & Вас-ева & $\begin{array}{l}9,50 / 146 \\
148 / 125\end{array}$ & $\begin{array}{l}9,38 / 140 \\
135 / 120\end{array}$ & $\begin{array}{l}9,17 / 135 \\
125 / 110\end{array}$ & $-33 c$ \\
\hline 4 & Гев-ов & $\begin{array}{c}11,38 / 150 \\
145 / 118\end{array}$ & $\begin{array}{c}11,17 / 143 \\
138 / 113\end{array}$ & $\begin{array}{l}10,50 / 135 \\
127 / 105\end{array}$ & $-32 c$ \\
\hline 5 & Пр-ова & $\begin{array}{l}10.05 / 148 \\
146 / 122 \\
\end{array}$ & $\begin{array}{l}9,45 / 140 \\
138 / 118 \\
\end{array}$ & $\begin{array}{l}9,23 / 134 \\
130 / 110 \\
\end{array}$ & $-42 c$ \\
\hline 6 & Бек-ов & $\begin{array}{l}11,45 / 146 \\
148 / 122\end{array}$ & $\begin{array}{c}11.28 / 136 \\
138 / 116\end{array}$ & $\begin{array}{l}11,06 / 124 \\
128 / 107\end{array}$ & $-39 c$ \\
\hline 7 & Пет-ов & $\begin{array}{l}12.03 / 150 \\
146 / 126\end{array}$ & $\begin{array}{c}11,47 / 142 \\
137 / 118\end{array}$ & $\begin{array}{c}11.23 / 134 \\
128 / 110\end{array}$ & $-40 c$ \\
\hline 8 & 0жи-ев & $\begin{array}{c}11,34 / 140 \\
145 / 123\end{array}$ & $\begin{array}{c}11,17 / 132 \\
136 / 118\end{array}$ & $\begin{array}{c}10,53 / 125 \\
128 / 110\end{array}$ & $-41 c$ \\
\hline 9 & Мор-ва & $\begin{array}{l}10,18 / 150 \\
145 / 125\end{array}$ & $\begin{array}{l}9,55 / 143 \\
137 / 117\end{array}$ & $\begin{array}{l}9,32 / 136 \\
125 / 110\end{array}$ & $-46 c$ \\
\hline \multicolumn{6}{|c|}{ Кросс } \\
\hline 1 & Мер-ов & $\begin{array}{l}11,40 / 145 \\
145 / 125\end{array}$ & $\begin{array}{c}11,48 / 136 \\
136 / 118\end{array}$ & $\begin{array}{c}10,40 / 127 \\
125 / 110\end{array}$ & $-60 c$ \\
\hline 2 & Иб-ев & $\begin{array}{c}11,57 / 150 \\
150 / 130 \\
\end{array}$ & $\begin{array}{c}12,03 / 143 \\
140 / 120 \\
\end{array}$ & $\begin{array}{c}10,43 / 132 \\
130 / 110 \\
\end{array}$ & $-114 c$ \\
\hline 3 & Про-ина & $\begin{array}{l}10,20 / 145 \\
145 / 125\end{array}$ & $\begin{array}{l}10,23 / 137 \\
136 / 115\end{array}$ & $\begin{array}{l}9,17 / 127 \\
125 / 110\end{array}$ & $-63 c$ \\
\hline 4 & Фин-ер & $\begin{array}{c}11,30 / 146 \\
140 / 125\end{array}$ & $\begin{array}{c}11,33 / 135 \\
1351115\end{array}$ & $\begin{array}{c}10,53 / 127 \\
120 / 105\end{array}$ & $37 c$ \\
\hline 5 & Кру-ов & $\begin{array}{l}11,45 / 150 \\
146 / 126\end{array}$ & $\begin{array}{l}11,44 / 142 \\
135 / 115\end{array}$ & $\begin{array}{l}10,51 / 133 \\
125 / 106\end{array}$ & $-54 c$ \\
\hline 6 & Шлю-ева & $\begin{array}{c}10,34 / 148 \\
148 / 128\end{array}$ & $\begin{array}{l}10,30 / 140 \\
136 / 116\end{array}$ & $\begin{array}{l}9,51 / 133 \\
125 / 105\end{array}$ & $-43 c$ \\
\hline 7 & Ива-на & $\begin{array}{c}10,28 / 145 \\
145 / 125\end{array}$ & $\begin{array}{l}10,23 / 136 \\
135 / 125\end{array}$ & $\begin{array}{l}9,41 / 124 \\
120 / 105\end{array}$ & $-53 c$ \\
\hline 8 & Чу-ва & $\begin{array}{c}10,33 / 145 \\
150 / 130 \\
\end{array}$ & $\begin{array}{c}10,38 / 134 \\
140 / 120 \\
\end{array}$ & $\begin{array}{l}9,49 / 125 \\
130 / 110 \\
\end{array}$ & $-44 c$ \\
\hline 9 & Три-ов & $\begin{array}{c}12.00 / 148 \\
145 / 128\end{array}$ & $\begin{array}{c}11,58 / 137 \\
135 / 118\end{array}$ & $\begin{array}{c}10,43 / 126 \\
125 / 110\end{array}$ & $-117 c$ \\
\hline
\end{tabular}

шаются показателей АД. Применение нетрадиционных подходов в подготовке студентов циклического отделения, технического вуза, вносит новизну в учебный процесс по программе «Физическая культура».

\section{Перспективы Аальнейших исследований}

Использование лыжероллеров и бега по сильнопересеченной местности можно рекомендовать и для студентов других отделений, это будет способствовать улучшению результатов в беге на выносли- вость при сдаче нормативов, в условиях технического вуза, это открывает дополнительные возможности использования локомоторных упражнений для улучшения сердечно-сосудистой и дыхательной систем. Когда традиционные методы работы со студентами на занятиях по физической культуре, не позволяют полностью раскрыть их потенциал в учебно-тренировочном процессе обучения. Наши дальнейшие исследования, будут направлены на изучение данной проблемы, будут подобраны и апробированы новые методики работы со студентами 


\section{ЛИТЕРАТУРА}

1. Абрамова Г.С. Возрастная психология: Учебное пособие для студентов вузов. - М.: Академический проект; Екатеринбург: Деловая книга, $2010 .-21$.

2. Ашмарин Б.А., Виноградов Ю.А., Вяткина 3.Н. и др. Теория и методики физического воспитания: учеб. для студентов фак. физ. культуры пед. ин-тов по спец. 03.03 «Физ. культура»: / под ред. Б.А. Ашмарина.- М.: Просвещение, 2000.-287.

3. Желобкович М.П. Оздоровительно-развивающий подход к физическому воспитанию студенческой молодёжи: Учеб.- методическое пособие / М.П. Желобкович, Р.И. Купчиной. - Мн., 2004. - 212 с.

4. Иссурин В.Б. Блоковая периодизация спортивной тренировки.-М.,2010

5. Лотоненко А.В. Физическая культура и спортивная работоспособность студентов. Воронеж. 1986., С.11-17

6. Мосин И.В., Мосина И.Н., Морозов Н.А. Развитие выносливости у студентов на занятиях по легкой атлетике в вузе: Учеб. методическое пособие/И.В. Мосин, И.Н. Мосина, Н.А. Морозов.-М., 2005.

7. Мосин И.В., Мосина И.Н., Есаулов М.Н. Подготовка бегунов на средние дистанции в группах спортивного совершенствования в условиях технического вуза: Учеб. методическое пособие/И.В. Мосин, И.Н. Мосина, М.Н. Есаулов.-М.,2018.

8. Мосин И.В., Мосина И.Н., Есаулов М.Н. Поурочное планирование учебного материала на занятиях по легкой атлетике для развития выносливости со студентами в условиях технического вуза: Учеб. методическое пособие /И.В. Мосин И.В, И.Н. Мосина, М.Н. Есаулов.-М., 2019.

9. Петров А.Я., Шестакова Т.Н. Основы управления учебным процессом физического воспитания студентов технических вузов: метод. пособие. Мн, 1981., C.9-19.

10. Тимофеев А.А. Оптимизация учебно-тренировочного процесса по физическому воспитанию студентов 17-18 лет в условиях технического вуза: автореф. дис. ... канд.пед.наук. Мн., 1988

11. Янсен П. ЧСС, лактат и тренировки на выносливость/ Пер. с англ.- Мурманск: Изда-во «Туолома», 2006.

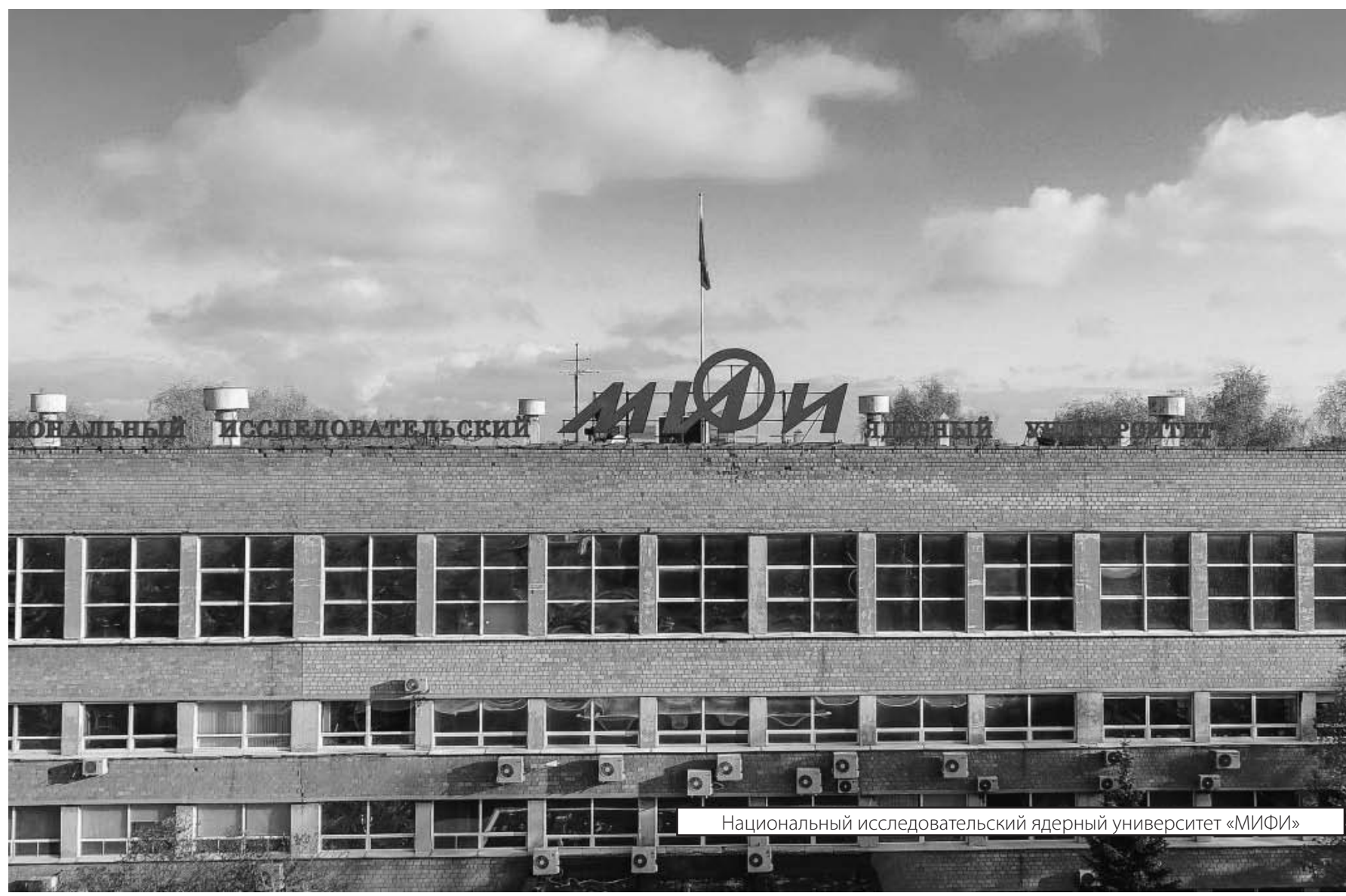

